\title{
Bilateral spontaneous rupture of anterior lens capsules in a middle-aged woman
}

This article was published in the following Dove Press journal:

Clinical Ophthalmology

26 November 2012

Number of times this article has been viewed

\author{
Chandrakanthan \\ Hemalatha ${ }^{1,2}$ \\ Hamzah Norhafizah' \\ Ismail Shatriah² \\ 'Department of Ophthalmology, \\ Hospital Tengku Ampuan Rahimah, \\ Selangor, Malaysia; ${ }^{2}$ Department of \\ Ophthalmology, School of Medical \\ Sciences, Universiti Sains Malaysia, \\ Kubang Kerian, Kelantan, Malaysia
}

Correspondence: Ismail Shatriah Department of Ophthalmology, School of Medical Sciences, Universiti Sains Malaysia, 16I50 Kubang Kerian, Kelantan, Malaysia

Tel +609767 6354

Fax +609765 3370

Email shatriah@kck.usm.my
Abstract: Hypermature cataracts are commonly seen in developing countries. Spontaneous rupture of the anterior capsule, resulting in dislocation of the lens nucleus into the anterior chamber, presents rarely in hypermature cataracts. We describe a middle-aged woman who presented with spontaneous anterior dislocation of the nucleus in both eyes. The presence of calcification spots in the posterior capsule at the pupillary edge strongly suggested that our patient had hypermature cataracts. It is important to highlight this uncommon cause of nucleus dislocation in a patient with no previous history of ocular trauma.

Keywords: dislocation of the nucleus, anterior chamber, hypermature cataract

\section{Introduction}

A hypermature cataract, or morgagnian cataract, is an end stage in the process of age-related cataract formation. It occurs when the cortical lens fibers become liquefied and produce milky fluids. This condition leads to numerous potentially blinding conditions, including lens-induced uveitis, acute phacomorphic glaucoma, and phacolytic glaucoma. Spontaneous lens dislocation into the vitreous cavity ${ }^{1-3}$ and absorption of the lens material $1^{4,5}$ have been described as complications of hypermature cataracts.

We report a case of spontaneous rupture of the anterior lens capsule in a middle-aged woman with hypermature cataracts, who presented to us with nucleus dislocations in the anterior chambers of both eyes. It is important to highlight this rare presentation because it may lead to potential errors in identifying causes of nucleus dislocation, especially when a history of trauma is absent.

\section{Case report}

A 52-year-old Malay woman who was a known case of thyrotoxicosis presented with vision that had been poor in both eyes for 5 years and that was worsening in severity. There was no history of recurrent eye redness or eye pain. She denied having a history of eye trauma or of wearing glasses. She was the first-born child of nonconsanguineous parents, in a family of five.

On examination, the visual acuity in both eyes was 6/60. Slit-lamp examination revealed clear corneas in both eyes. The nuclei were small, and each had dislocated into the anterior chamber of the respective eye. Calcification spots in the capsular tags were clearly visible in the pupillary margins, suggesting they were from ruptured, hypermature cataracts in both eyes, which had resulted in anterior dislocation of each nucleus (Figure 1). The anterior chambers were quiet, and no sign of uveitis was noted. 


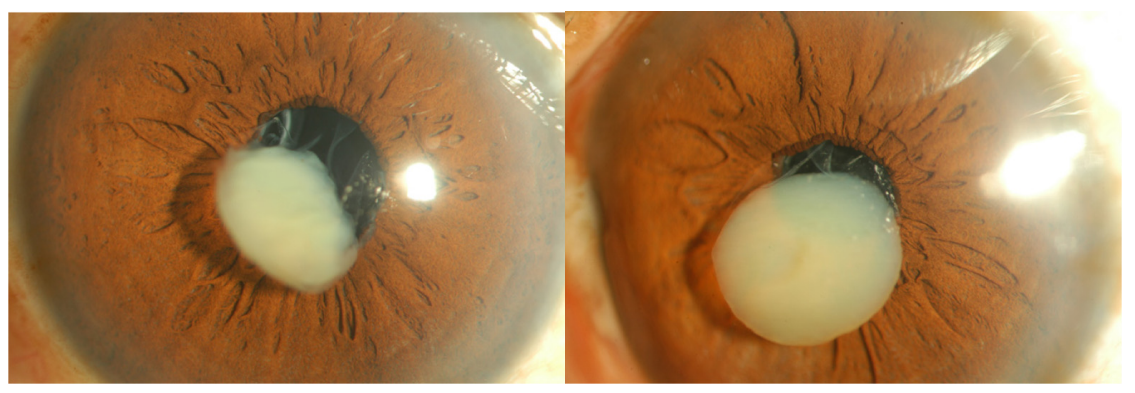

Figure I Anterior segment photographs show anterior dislocation of nucleus with multiple calcified spots in the remnant of posterior capsules of right and left eyes respectively.

There was no lenticular-corneal touch noted, nor was any pseudoexfoliative material at the pupillary margins observed. The fundus was not visible, as she had poorly dilating pupils in both eyes. Her intraocular pressure was $12 \mathrm{mmHg}$ in both eyes. B-scan ultrasound showed a bilaterally flat retina.

She was of normal stature, cardiovascular and skeletal assessments were normal, and hearing test results were normal. The patient was advised to have intracapsular cataract and intraocular lens implantations in both eyes, however she refused, and defaulted on her follow-up.

\section{Discussion}

Despite numerous health awareness strategies and campaigns, hypermature cataracts are still frequently seen in Malaysia. Based on our experience, patients' refusal of modern ophthalmic treatment is the main reason, especially when their fellow eye is seeing well.

In a hypermature cataract, the milky fluid from the cortical matter flows into the anterior chamber through a minute break in the lens capsule, resulting in anterior uveitis and phacolytic glaucoma. In contrast, a minute break in the posterior capsule may result in gradual absorption of lens matter without complications. This leaves a hard, shrunken nucleus which may cause the spontaneous dislocation of the lens, especially into the vitreous cavity, and this is attributable to weak zonules. ${ }^{1-3}$

Spontaneous rupture of the lens capsule in a hypermature cataract is extremely uncommon. ${ }^{67}$ Based on a PubMed search, we noted a similar case was reported by Ming in 1963. ${ }^{7}$ Ming described the expulsion of the nucleus following rupture of an anterior capsule in a 50-year-old woman who had a hypermature cataract in the left eye, and Ming attributed her poor final visual acuity to an unknown cause of optic atrophy.

Our patient presented with bilateral anterior dislocations of both lenses' nuclei. The presence of multiple calcified spots was indicated by the lens-capsule remnants visible at each eye's pupillary edge. This suggested that hypermature cataracts were the most likely cause of our patient's ruptured anterior lens capsules. Both dislocated nuclei were suspended at the pupillary area.

We postulated that the cortical matter had probably been absorbed much earlier or that there had been a posterior leak into the vitreous cavity. Our patient was asymptomatic, and did not show sign of lens-induced uveitis or increased intraocular pressure. However, it was relatively difficult to determine her postoperative visual potential. We were unable to assess her optic nerve and retinal status due to poor pupillary dilation in both eyes. It is unfortunate that she declined surgical intervention and missed her follow-up.

It is quite alarming that our patient, a 52-year-old woman, had developed hypermature cataracts in both eyes. There were no systemic signs or metabolic abnormalities to explain her ocular condition. We did not perform a genetic work-up due to her financial constraints.

Spontaneous rupture of anterior lens capsules have also been described in younger patients with chronic uveitis, ${ }^{8}$ polar cataract, ${ }^{9,10}$ and other systemic illnesses, such as Alport syndrome $\mathrm{e}^{11-13}$ and Marshall syndrome. ${ }^{14} \mathrm{~A}$ complete systemic assessment and genetic work-up are essential when a systemic disease is suspected, especially when nephritis (in Alport syndrome) and connective tissue disease (in Marshall syndrome) are encountered.

\section{Conclusion}

A spontaneous rupture of the anterior capsule is sometimes misleading when it occurs in younger and pre-senile age groups. Spontaneous rupture of the anterior lens capsule that leads to anterior dislocation of the nucleus is a rare complication of hypermature cataracts. Patients' negligence and refusal to accept modern treatment remain the sole reasons for this avoidable condition in our patients.

\section{Disclosure}

The authors report no conflicts of interest in this work. 


\section{References}

1. Seo MS, Yoon KC, Lee CH. Phacofragmentation for the treatment of a completely posterior dislocation of the total crystalline lens. Korean J Ophthalmol. 2002;16(1):32-36.

2. Haymet BT. Removal of a dislocated hypermature lens from the posterior vitreous. Aust N Z J Ophthalmol. 1990;18(1):103-106.

3. Bass LJ, Potter JW. A case of spontaneous dislocated lenses. Am J Optom Physiol Opt. 1985;62(5):352-356.

4. Uemura A, Sameshima M, Nakao K. Complications of hypermature cataract: spontaneous absorption of lens material and phacolytic glaucoma-associated retinal perivasculitis. Jpn J Ophthalmol. 1988;32(1): $35-40$.

5. Mohan M, Bartholomew RS. Spontaneous absorption of a cataractous lens. Acta Ophthalmol Scand. 1999;77(4):476-477.

6. Ballen PH, Hughes WL. Spontaneous rupture of lens capsule in hypermature (morgagnian type) cataract. Am J Ophthalmol. 1955; 39(3):403-405.

7. Ming AL. Spontaneous rupture of the anterior capsule of a hypermature lens. Singapore Med J. 1963;3:127-130.

8. Allen JC, De Venecia G. Spontaneous lens capsule rupture with uveitis. Am J Ophthalmol. 1969;67(1):144-149.
9. Ashraf H, Khalili MR, Salouti R. Bilateral spontaneous rupture of posterior capsule in posterior polar cataract. Clin Experiment Ophthalmol. 2008;36(8):798-800.

10. Ho SF, Ahmed S, Zaman AG. Spontaneous dislocation of posterior polar cataract. J Cataract Refract Surg. 2007;33(8):1471-1473.

11. Olitsky SE, Waz WR, Wilson ME. Rupture of the anterior lens capsule in Alport syndrome. JAAPOS. 1999;3(6):381-382.

12. Wilson ME Jr, Trivedi RH, Biber JM, Golub R. Anterior capsule rupture and subsequent cataract formation in Alport syndrome. JAAPOS 2006;10(2):182-183.

13. Gupta A, Ramesh Babu K, Srinivasan R, Mohanty D. Clear lens extraction in Alport syndrome with combined anterior and posterior lenticonus or ruptured anterior lens capsule. J Cataract Refract Surg 2011;37(11):2075-2078.

14. Endo S, Hashimoto Y, Ishida N, Kusano Y, Ohkoshi K, Yamaguchi T. [A case of Marshall syndrome with secondary glaucoma due to spontaneous rupture of the lens capsule]. Nihon Ganka Gakkai Zasshi. 1998;102(1):75-79. Japanese.
Clinical Ophthalmology

\section{Publish your work in this journal}

Clinical Ophthalmology is an international, peer-reviewed journal covering all subspecialties within ophthalmology. Key topics include: Optometry; Visual science; Pharmacology and drug therapy in eye diseases; Basic Sciences; Primary and Secondary eye care; Patien Safety and Quality of Care Improvements. This journal is indexed on

Submit your manuscript here: http://www.dovepress.com/clinical-ophthalmology-journal

\section{Dovepress}

PubMed Central and CAS, and is the official journal of The Society of Clinical Ophthalmology (SCO). The manuscript management system is completely online and includes a very quick and fair peer-review system, which is all easy to use. Visit http://www.dovepress.com/ testimonials.php to read real quotes from published authors. 